\title{
Investigation on a high-stratified direct injection spark ignition (DISI) engine fueled with methanol under a high compression ratio
}

\author{
Yaopeng $\mathrm{Li}^{\text {a, }}{ }^{*}$, Xue-Song Bai a ${ }^{\text {a }}$, Martin Tunér ${ }^{\text {b }}$, Hong G. Im ${ }^{\text {c }}$, Bengt Johansson ${ }^{\text {c }}$ \\ ${ }^{a}$ Division of Fluid Mechanics, Dept. Energy Sciences, Lund University \\ ${ }^{b}$ Division of Combustion Engines, Dept. Energy Sciences, Lund University \\ ${ }^{c}$ Clean Combustion Research Center, King Abdullah University of Science and Technology \\ * Corresponding author: Yaopeng Li, Division of Fluid Mechanics, Dept. Energy Sciences, Lund University, \\ yaopeng.li@energy.lth.se
}

Citation: Li Y, Bai X S, Tunér M, Im, H. G., Johansson, B. Investigation on a high-stratified direct injection spark ignition (DISI) engine fueled with methanol under a high compression ratio. Applied Thermal Engineering, 2019, 148:352-362.

\begin{abstract}
This paper reports an investigation of a highly stratified methanol direct injection spark ignition (DISI) engine with a high compression ratio. The effects of the start of injection (SOI), spray-included angle, injection pressure, and spark timing (ST) on in-cylinder flow, fuel distribution, flame propagation, and engine performance are evaluated in detail. The combustion process of methanol DISI engine is very sensitive to the variation of SOI, which is closely associated with the in-cylinder turbulence and the fuel/air mixing. It is found that retarding SOI shows the similar effects on combustion process as reducing spray-included angle, which indicates that the effects of SOI are more related to the spray target (i.e., fuel distribution). The injection pressure affects the combustion process mainly through the impact on the fuel distribution in the cylinder. The flame propagates from the spark plug towards the cylinder axis along the in-cylinder swirl direction, and more fuel mass in the piston bowl promotes the flame propagation. Thus, more retarded SOI, smaller spray-included angle, and lower injection pressure are suggested at low loads to enrich the fuel concentration in the bowl to achieve a stable combustion. Under medium load, indicated thermal efficiency (ITE), peak pressure rise rate (PPRR), and nitrogen oxides $\left(\mathrm{NO}_{\mathrm{x}}\right)$ emissions can be improved with advanced SOI. ITE can also be improved by advancing ST with a slight penalty on PPRR and $\mathrm{NO}_{\mathrm{x}}$. This study demonstrates the potential of simultaneously optimizing fuel injection and ST to improve engine performance.
\end{abstract}

Keywords: direct injection spark ignition; highly stratified methanol fuel; high compression ratio; spray/bowl interaction; flame propagation; engine performance 


\section{Introduction}

Simultaneous improvements in fuel efficiency and exhaust emissions have become an imperative demand more than ever to comply with the more stringent requirements in the future. Although the fuel efficiency of conventional compression ignition (CI) engines is higher than that of port fuel injection (PFI) spark ignition (SI) engines due to higher compression ratio, the high nitrogen oxides $\left(\mathrm{NO}_{\mathrm{x}}\right)$ and soot emissions are serious problems. Thus, advanced combustion strategies are desirable to combine the satisfactory features of both SI and CI engines. Direct injection spark ignition (DISI) engines are a promising candidate since they are characterized by high compression ratio, low pumping loss, high volumetric efficiency, and flexible charge stratification [1]. Compared with PFI engines, DISI engines have been demonstrated to achieve higher fuel efficiency, faster transient response, and lower emissions under various operating conditions [2].

The spray-guided combustion systems are widely adopted in the current DISI engines, which is developed from wall-guided and air-guided systems. In spray-guided DISI engines, the preparation of fuel stratification is achieved by directly utilizing the spray momentum rather than relying on chamber wall or in-cylinder flow. As a result, more stable combustion can be achieved, and fuel impingement can be effectively avoided. Johansson et al. [3] summarized that the advantages of spray-guided DISI engines over PFI engines in fuel efficiency are mostly ascribed to the lower pumping loss, reduced wall heat loss, more favorable charge properties, and increased charge cooling. Alkidas et al. [4] studied the contributions of various factors to the fuel efficiency gain of DISI engines, and they found that the primary positive contributors are the reduced pumping loss, more favorable mixture gas properties (e.g. specific heat ratio), and higher compression ratio.

Besides improving the fuel efficiency of internal combustion engines, the application of alternative fuels can also effectively reduce oil depletion and greenhouse gases. Fueling alcohols in DISI engines has been demonstrated to improve fuel efficiency and reduce engine-out $\mathrm{CO}_{2}$ emissions [5]. Especially, when the alternative fuels are produced from biomass, a nearly closed carbon life cycle can be built with very low $\mathrm{CO}_{2}$ production. Due to the high research octane number (RON), the high latent heat of evaporation, and the fast laminar flame speed, alcohols show high knock resistance [6]. As a result, a higher compression ratio can be allowed for alcohols, benefiting the increase of fuel efficiency. Moreover, the high latent heats of evaporation of alcohols also help reduce $\mathrm{NO}_{\mathrm{x}}$ emissions, and the oxygen content in alcohols promotes the complete oxidation of fuel. One of the alcohols, i.e., ethanol, has been well studied over the past decades, it is widely used in commerce by blending with gasoline (the volume fraction of ethanol is usually less than $20 \%$ ) without modifying the existing combustion systems.

Complete replacement of commercial fossil fuel with the renewable fuels is the long-term goal, while no single fuel has such large production to fulfill the task so far. So the diversity of renewable fuels will be necessary in the future. Besides the commercialized ethanol, methanol is also an attractive candidate for DISI engines for its wide range of resources [7, 8]. Methanol can be produced not only from fossil oil, but also from biomass and renewable energy sources. Since methanol is easy to be synthesized, it is a perfect energy carrier which converts solar or wind energy into the chemical energy of fuel. Moreover, methanol is liquid at the standard temperature and pressure, 
making it an efficient way of storing and distributing energy [9].

Moreover, there are many similarities in the fuel property between methanol and ethanol, which allows for the use of both fuels in the same engine without hardware modification, i.e., the flex-fuel engines. In fact, methanol shows more potential than ethanol for DISI engines. First, although the RON of methanol is comparable to that of ethanol, the more significant cooling effect of methanol shows stronger knock resistance and larger $\mathrm{NO}_{\mathrm{x}}$ reduction due to the higher latent heat of evaporation of methanol than ethanol. Second, DISI engines usually suffer from high particulate matter (PM) emissions deriving from the inhomogeneous combustion, while the oxygen content in methanol molecule is larger than ethanol, and methanol contains no carbon-carbon bond, both of which can effectively eliminate the PM emissions in DISI engines [10].

Due to these attractive properties, methanol has become an attractive renewable fuel recently. Liu et al. [11] investigated the effect of methanol/gasoline blends on engine performance in a three-cylinder PFI engine. They found that the brake thermal efficiency was improved by blending more methanol, and both $\mathrm{HC}$ and $\mathrm{CO}$ emissions could be reduced with more methanol addition, even during cold start. Different from blending dual fuels, Liu et al. [12] separately injected methanol and gasoline through port and direct injection. It is found that methanol/gasoline dualfuel exhibited better anti-knock performance and achieved higher fuel efficiency compared with ethanol/gasoline. Vancoillie et al. [13] compared the engine performance of fueling pure methanol and gasoline in a DISI engine. They found that higher brake thermal efficiency and lower $\mathrm{HC}, \mathrm{CO}$, and $\mathrm{NO}_{\mathrm{x}}$ emissions were simultaneously achieved by fueling methanol instead of gasoline. Similar results were also obtained by Sileghem et al. [14] in a DISI engine; they found that fueling methanol demonstrated the better overall engine performance than ethanol, iso-butanol, and gasoline. Moreover, they noted that the engine-out PM emissions were the lowest for methanol among the four different fuels.

Although the application of methanol to DISI engines was explored before, these studies were generally conducted on a DISI engine designed for gasoline with a relatively low compression ratio (below 14:1). Due to the superior knock resistance of methanol, it is envisaged to be capable of operating at a higher compression ratio. At present, the combustion characteristics of methanol under high compression ratios remains unclear, and the potential of methanol to maximize the fuel efficiency of DISI engines is still unknown. Furthermore, it is known that incylinder fuel distribution has a significant impact on the ignition and flame propagation process. In practical engine operation, the in-cylinder fuel distribution is mainly controlled by the start of injection (SOI). In previous DISI studies, the SOI was mostly at a very early timing, so the in-cylinder fuel stratification at spark timing (ST) is quite low. There is little work dedicated to studying the flame propagation of a highly stratified methanol DISI engine with a late SOI. Motivated by these, a highly stratified methanol DISI engine with a high compression ratio is investigated in this study. Due to the highly stratified fuel distribution, the combustion process and engine performance are sensitive to the variation of the relevant injection parameters, including SOI, spray-included angle, and injection pressure, which will be investigated in detail. The ST determines the onset time of ignition, so it is also explored here. This paper focuses on the combustion behavior of the highly stratified methanol under a high compression ratio, and the 
mechanisms of the operating parameters affecting the fuel distribution and flame propagation. Based on the understanding, further improvements of DISI engine performance are proposed to meet the more stringent requirements on fuel efficiency and emissions in the future.

\section{Engine experimental setup}

The experiment is conducted on a modified six-cylinder Scania D13 heavy-duty engine [15], with only one cylinder fired and the rest in motored run. A schematic diagram of the engine, air intake and exhaust manifolds including the exhaust gas recirculation (EGR) control system in the test cell is shown in Fig. 1. In consideration of the high knock resistance of methanol, a high geometry compression ratio of 17.3 is adopted to improve the fuel efficiency. The piston geometry at top dead center (TDC) can be seen in Fig. 2a, and more information about the engine specifications can be found in Table 1.

Table 1 Engine specifications

\begin{tabular}{ll}
\hline Displacement & $2124 \mathrm{~cm}^{3}$ \\
Bore & $130 \mathrm{~mm}$ \\
Stroke & $160 \mathrm{~mm}$ \\
Connecting rod & $255 \mathrm{~mm}$ \\
Geometry compression ratio & $17.3: 1$ \\
Number of valves & 4 \\
Swirl ratio & 2.1 \\
Intake valve closing (IVC) & $-141^{\circ} \mathrm{CA}$ ATDC \\
Exhaust valve opening (EVO) & $137^{\circ} \mathrm{CA}$ ATDC \\
Injector model & XPI \\
Injector type & Solenoid \\
Number of nozzles & 10 \\
Nozzle hole diameter & $0.175 \mathrm{~mm}$ \\
Spray-included angle & $148^{\circ}$ \\
Distance between spark plug and injector & $37 \mathrm{~mm}$ \\
\hline
\end{tabular}

An XPI common rail injector is mounted in the center of the cylinder, which can provide the injection pressure up to 2200 bar and at most triple injections in one cycle. In order to compensate for the small lower heating value (LHV) of methanol, ten nozzle holes are drilled in the injector to provide an umbrella-shaped fuel sprays with an included angle of $148^{\circ}$, cf. Fig. 2 a for half of the spray-included angle. The cylinder head is modified to install an off-center spark plug. The distance from the spark plug to the cylinder axis (also the injector axis) is $37 \mathrm{~mm}$ along X- 
axis. The relative location of spark plug and injected spray can be seen in Fig. 2. In the experiment, Infinium R655 lubricity additive was blended with methanol at a ratio of $4 \mathrm{mg}$ to 20 liters to protect the fueling equipment.



Fig. 1 Engine setup schematic
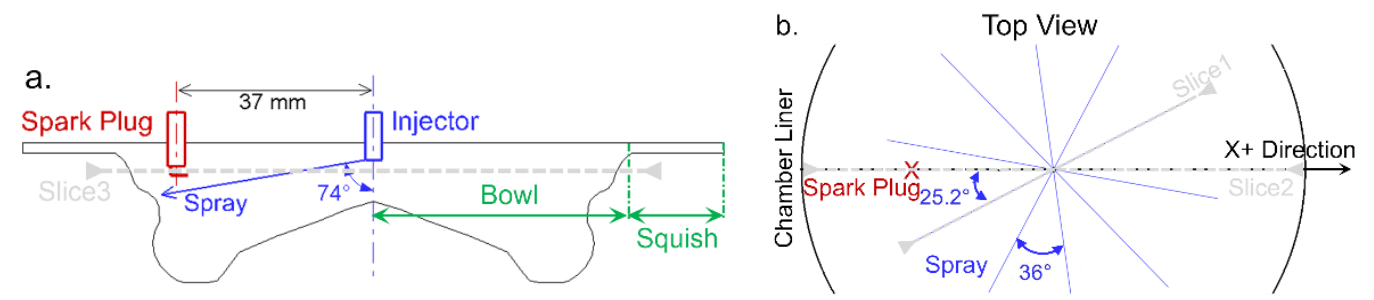

Fig. 2 Piston geometry, locations of spark plug, injector, and three characteristic cross-section slices

Table 2 Engine operating conditions

\begin{tabular}{ll}
\hline Engine speed & $1200 \mathrm{rpm}$ \\
IMEP & $8 \mathrm{bar}$ \\
Lambda $(\lambda)$ & 1.5 \\
Intake pressure & $1.0 \mathrm{bar}$ \\
Intake temperature & $85{ }^{\circ} \mathrm{C}$ \\
SOI & $-23--31{ }^{\circ} \mathrm{CA}$ ATDC \\
Injection pressure & $2000 \mathrm{bar}$ \\
Spark timing & $-2{ }^{\circ} \mathrm{CA}$ ATDC \\
EGR rate & $0 \%$ \\
\hline
\end{tabular}

In order to clearly show the processes of in-cylinder spray and combustion, three characteristic cross-section slices are created. As seen in Fig. 2b, Slice 1 is a vertical spray section, which is used to characterize the spray 
development and spray-wall interaction. Slice 2 is a vertical plane through the $\mathrm{X}$ axis, and Slice 3 is a horizontal plane through spark plug (see Fig. 2a), both of them are used to illustrate the ignition and flame propagation.

The operating conditions in the experiment are given in Table 2. The engine is operated at medium load and speed (indicated mean effective pressure, IMEP, of 8 bar and $1200 \mathrm{rpm}$ ). The intake pressure and temperature are kept constant. In order to maximize fuel efficiency, no EGR is introduced in this study to keep the high specific heat ratio [16]. The high injection pressure is used to shorten the injection duration to compensate the small LHV of methanol. The high injection pressure is also beneficial to improve spray atomization and mixture preparation, especially for the reduction of PM emissions [17]. The relatively late SOI is used to couple the preparation of fuel/air mixture with the ignition event to effectively control the combustion process. Although the interval between the end of injection and ST is rather short, it is shown to be long enough for methanol/air premixing in the experiment due to the high ambient pressure and temperature during injection, the high injection pressure, as well as the adorable physical property of methanol for atomization and evaporation [18]. Due to the limitation of hardware tolerance, the engine operation is made to satisfy the peak pressure rise rate (PPRR) of $10 \mathrm{bar} /{ }^{\circ} \mathrm{CA}$ or lower, the combustion efficiency of $97 \%$ or higher, and the coefficient of variation (COV) of IMEP of $10 \%$ or lower. Within these constraints, the SOI is swept in the experiment while keeping other parameters constant. Due to the high laminar flame speed of methanol and the absence of EGR, the ST is retarded to around TDC to avoid excessively high PPRR.

\section{Numerical model}

The three-dimensional computational fluid dynamics (CFD) simulation software, CONVERGE [19] with enhanced sub-models, is adopted in this study to explore the spray and combustion processes in methanol DISI engines. The re-normalization group (RNG) $k-\varepsilon$ turbulence model [20] is used, which is particularly suited for the simulation of internal combustion engines. The hybrid Kelvin Helmholtz-Rayleigh Taylor (KH-RT) model [21] is employed to simulate the spray droplet breakup process. Within the characteristic breakup distance $\left(L_{b}\right)$, only $\mathrm{KH}$ instabilities are responsible for the drop breakup. Beyond the breakup length, both KH and RT instabilities are considered to model the second breakup. Developing from the basic probability model for stochastic collision, the no-time-counter (NTC) numerical scheme [22] is used to predict the spray collision. The change of droplet radius over time is described using the Frossling evaporation model [23], and the thermal transfer to a droplet is calculated by assuming the droplet temperature uniform. The spray-wall interaction is modeled by considering four different situations, including stick, rebound, spread, and splash [24].

The imposed stretch spark ignition model (ISSIM) [25] based on an Eulerian approach is used to simulate the spark ignition process. During the spark period, the released energy from spark is absorbed by the surrounding gas. Once the total energy received by the gas is larger than a critical energy, ignition will occur [19]. At the beginning of

ignition, a mass of burned gas $\left(m_{b g}^{i g n}\right)$ is assumed to be deposited around the spark plug according to the received energy by gas, and it is calculated as: 


$$
m_{b g}^{i g n}=C_{b g}\left\langle\frac{E_{i g n}}{C_{p} \times \Delta T_{i g n}}\right\rangle
$$

where $E_{i g n}$ is the received energy by gas, $C_{p}$ is the specific heat value at constant pressure, $\Delta T_{i g n}$ is a characteristic temperature of the plasma in the early instants ( $20000 \mathrm{~K}$ is chosen here), $C_{b g}$ is a coefficient used to correct the initial deposit mass, and bracket denotes an average in the cells within a sphere of radius of twice the spark gap. The distribution of deposited burned gas around the spark plug is given in volume fraction as:

$$
\bar{c}_{i g n}\left(x, t_{i g n}\right)=c_{0} \times \exp \left(-\left(\frac{\left|x-x_{s p k}\right|}{0.5 d_{i e}}\right)^{2}\right)
$$

where $x$ is the cell coordinate, $x_{s p k}$ is the location of spark plug, $d_{i e}$ is the spark gap length, and $c_{0}$ is selected to satisfy the following conservation equation:

$$
\int \rho_{b} \bar{c}_{i g n} d V=m_{b g}^{i g n}
$$

At the onset of ignition, the initial flame kernel is assumed to be a sphere and its radius is defined as:

$$
r_{b}^{i g n}=\left(\frac{3}{4 \pi} \int \bar{c}_{i g n} d V\right)^{1 / 3}
$$

The flame surface density $(\mathrm{FSD}, \Sigma)$, i.e., the flame surface area per volume, at the start of ignition is calculated:

$$
\Sigma_{\text {ign }}=C_{\text {surf }} \frac{3 \bar{c}}{r_{b}^{\text {ign }}}
$$

where $C_{\text {surf }}$ is an user-specified initial wrinkling value, which accounts for the non-perfect sphericity of the flame kernel, and $\bar{c}$ is the reaction progress variable.

After determining the radius and FSD of the initial flame kernel, the subsequent flame propagation process is modeled using the extended coherent flamelet model (ECFM) [26], based on the resolution of a transport equation for the FSD as:

$$
\frac{\partial \Sigma}{\partial t}+\frac{\partial u_{i} \Sigma}{\partial x_{i}}=\frac{\partial}{\partial x_{i}}\left(\left(\frac{\mu}{S c}+\frac{\mu_{t}}{S c_{t}}\right) \frac{\partial(\Sigma / \bar{\rho})}{\partial x_{i}}\right)+\left(P_{1}+P_{2}+P_{3}\right) \Sigma-D+P_{k}
$$

where $\mu$ and $\mu_{t}$ are the laminar and turbulent viscosity, $S c$ and $S c_{t}$ are the laminar and turbulent Schmidt number, $P_{1}$, $P_{2}$, and $P_{3}$ respectively account for the flame surface production by turbulent stretch, flame thermal expansion and curvature, and mean flow dilation. $D$ describes the loss of flame surface density due to consumption, $P_{k}$ is the spark source term. The extended Zel'dovich mechanism is used to predict the thermal $\mathrm{NO}_{\mathrm{x}}$ emissions [27]. Although the prediction of PM emissions is absent in this study, the previous studies [28, 29] provide the confidence that the PM emissions would be kept at a very low level in methanol DISI engines.

Automatic mesh generation is an attractive feature of CONVERGE, in which adaptive mesh refinement (AMR) can be used to refine mesh resolution based on different requirements. The AMR can not only be applied to some specific regions by fixed embedding, but also employed in the whole domain according to the gradients of temperature, velocity, and species concentration. Therefore, without relying on a small base cell size, a grid- 
independent prediction can be achieved with a relatively coarse base cell size by adopting a high-level AMR. In this study, the base cell size is $4 \mathrm{~mm}$, a 3-level AMR is adopted based on the temperature gradient of $2 \mathrm{~K}$ and velocity gradient of $1.5 \mathrm{~m} / \mathrm{s}$. Moreover, in order to accurately solve the spray flow and spark ignition, 3-level fixed embedding is employed to the cylindrical regions along spray direction and 5-level fixed embedding is applied to the spherical regions near the spark plug.

\section{Multi-dimensional model validation}

The engine setup in the numerical study is the same as that used in the experiments described in Section 2, except the geometry compression ratio is reduced from 17.3 to 16.5 through calibrating the motoring curve, which is likely due to blow-by. The simulation is performed in a closed cycle, i.e. from the intake valve closing (IVC) to exhaust valve opening (EVO), thus without considering the intake and exhaust stroke. The predicted pressure and heat release rate (HRR) under various SOIs are compared with the experimental data [15], as shown in Fig. 3. When ST and injection pressure are kept constant, both HRR and peak in-cylinder pressure decrease with the advanced SOI. The variations of pressure and HRR under different operating conditions in the experiment can be well replicated by the numerical model.
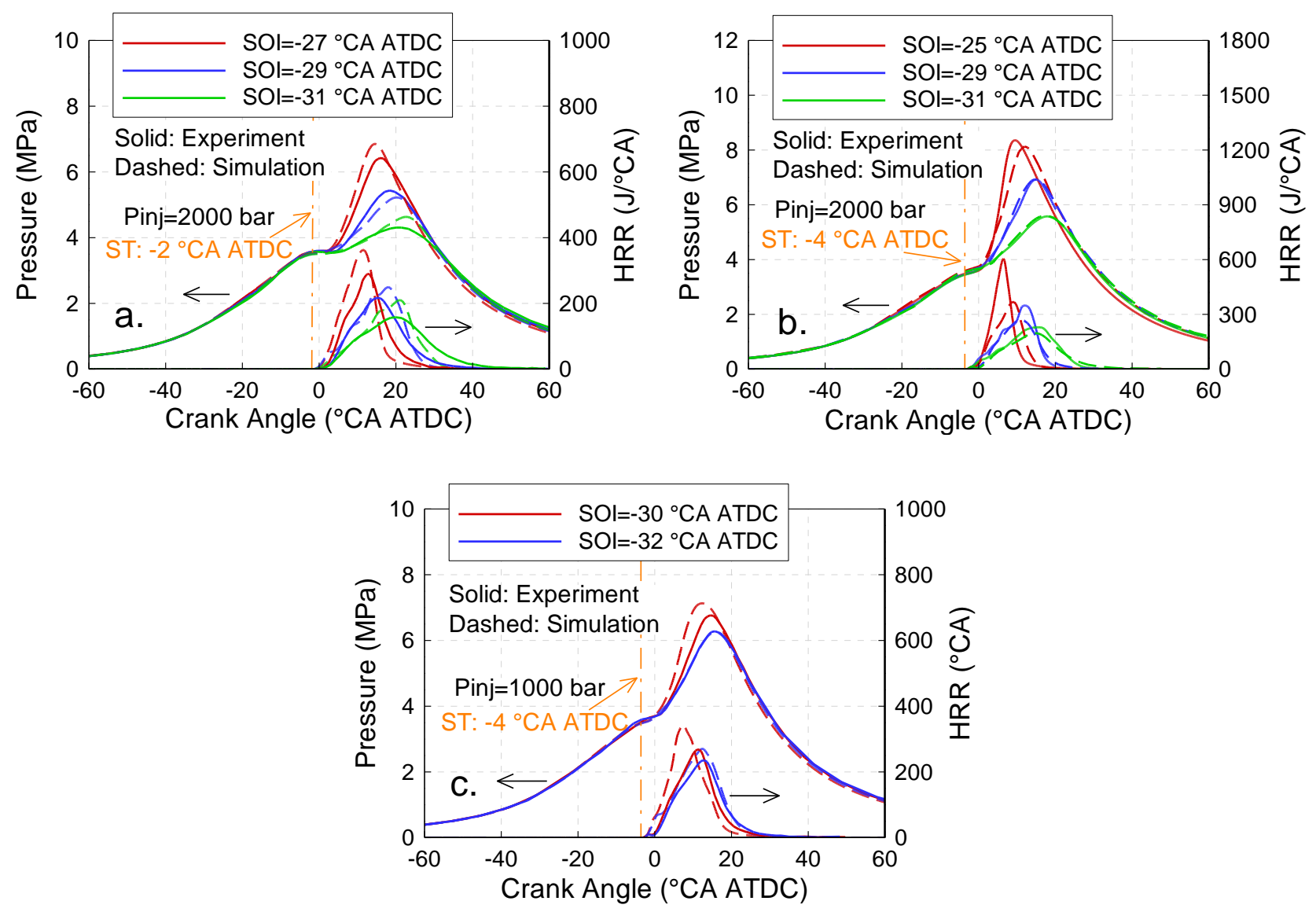

Fig. 3 Comparison of pressure and HRR between experiment and simulation under different operating conditions 
The predicted indicated thermal efficiency (ITE) and $\mathrm{NO}_{\mathrm{x}}$ emissions are compared to the experimental results, as shown in Fig. 4. Since HRR and peak pressure increase with the retarded SOI, the $\mathrm{NO}_{\mathrm{x}}$ emissions increases accordingly. As seen in Fig. 4a, with the retarded SOI, the ITE increases firstly and then decreases, the reason will be discussed later. Since the engine output work in the simulation is calculated from IVC to EVO rather than the whole cycle in the experiment, which causes the lower fuel efficiency than the experiment. The variation of ITE under various SOIs is well captured by the numerical model. Overall, although quantitative discrepancies exist between the simulations and the experiments, the consistent trend of the in-cylinder pressure, HRR, ITE, and $\mathrm{NO}_{\mathrm{x}}$ shown in the validation results demonstrates the reliability of the numerical model in qualitative analysis of methanol combustion process under different conditions in DISI engines.
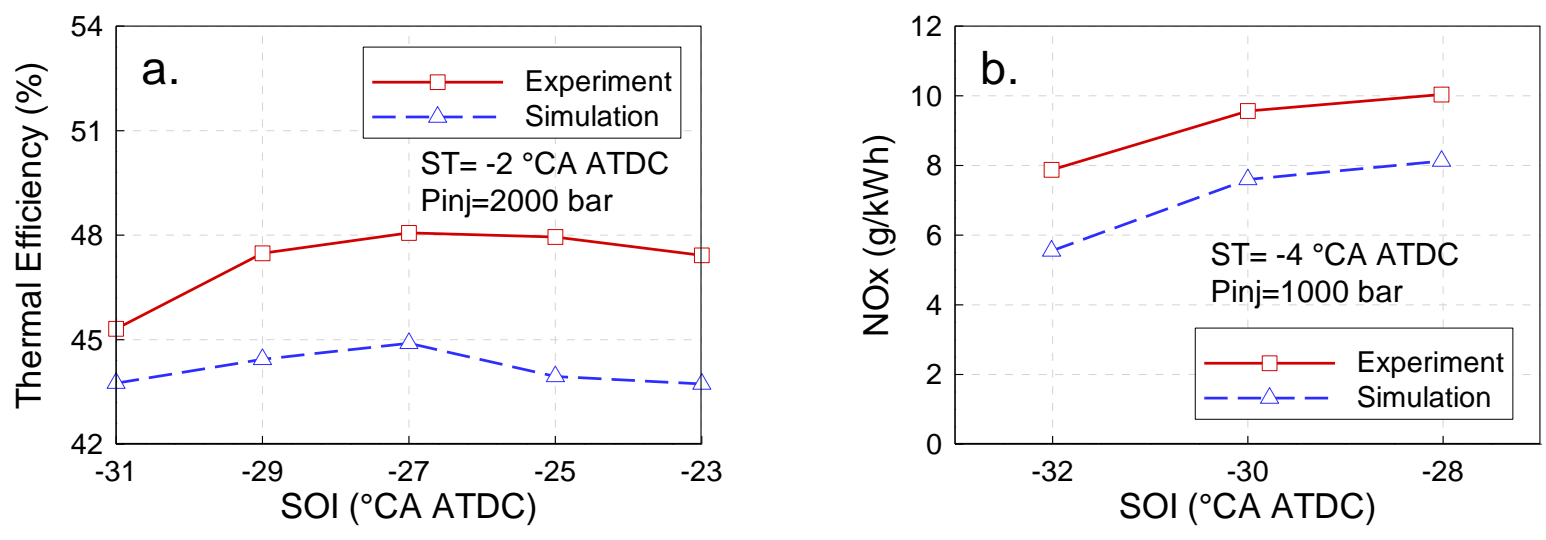

Fig. 4 Comparison of ITE and $\mathrm{NO}_{\mathrm{x}}$ emissions between experiment and simulation under different operating conditions

\section{Results and discussions}

\subsection{Effect of injection parameters}

\subsubsection{Effect of SOI}
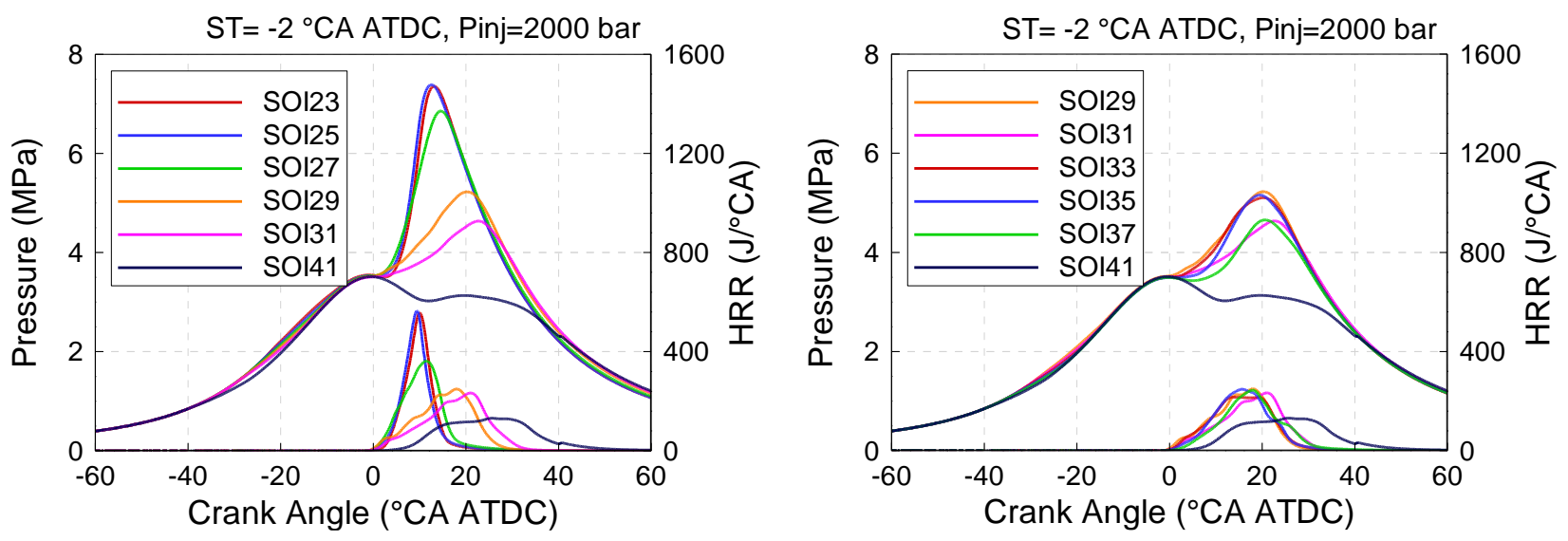

Fig. 5 In-cylinder pressure and heat release rate for different SOIs (SOIn denotes the SOI at $-n{ }^{\circ} \mathrm{CA}$ ATDC) 
In the following, the numerical model is used to investigate the combustion characteristics of methanol DISI engines at different operating conditions. First, the effects of SOI on the combustion process of methanol DISI engine are studied in detail, while all the other parameters are kept the same as Table 2. As seen in Fig. 5 (also in Fig. 3), the combustion process of methanol DISI engine is highly sensitive to the variation of SOI. Generally, the peak pressure gradually decreases with advanced SOI, as shown in Fig. 5a. However, a non-monotonic variation is observed for the SOI range from -33 to $-37{ }^{\circ} \mathrm{CA}$ ATDC. When SOI is advanced to $-41^{\circ} \mathrm{CA}$ ATDC, the flame propagation is so slow that the peak pressure is very low, resulting in very low fuel efficiency and high instability. Thus, only the SOI from -23 to $-37^{\circ} \mathrm{CA}$ ATDC is regarded as the operable range for this engine. We note that there is a $6{ }^{\circ} \mathrm{CA}$ difference in the operable SOI range between simulation (-23--37 ${ }^{\circ} \mathrm{CA}$ ATDC) and experiments (-23--31 ${ }^{\circ} \mathrm{CA}$ ATDC). This difference is attributed to the accuracy of the RANS model and the uncertainty of the initial and boundary conditions in the simulation.
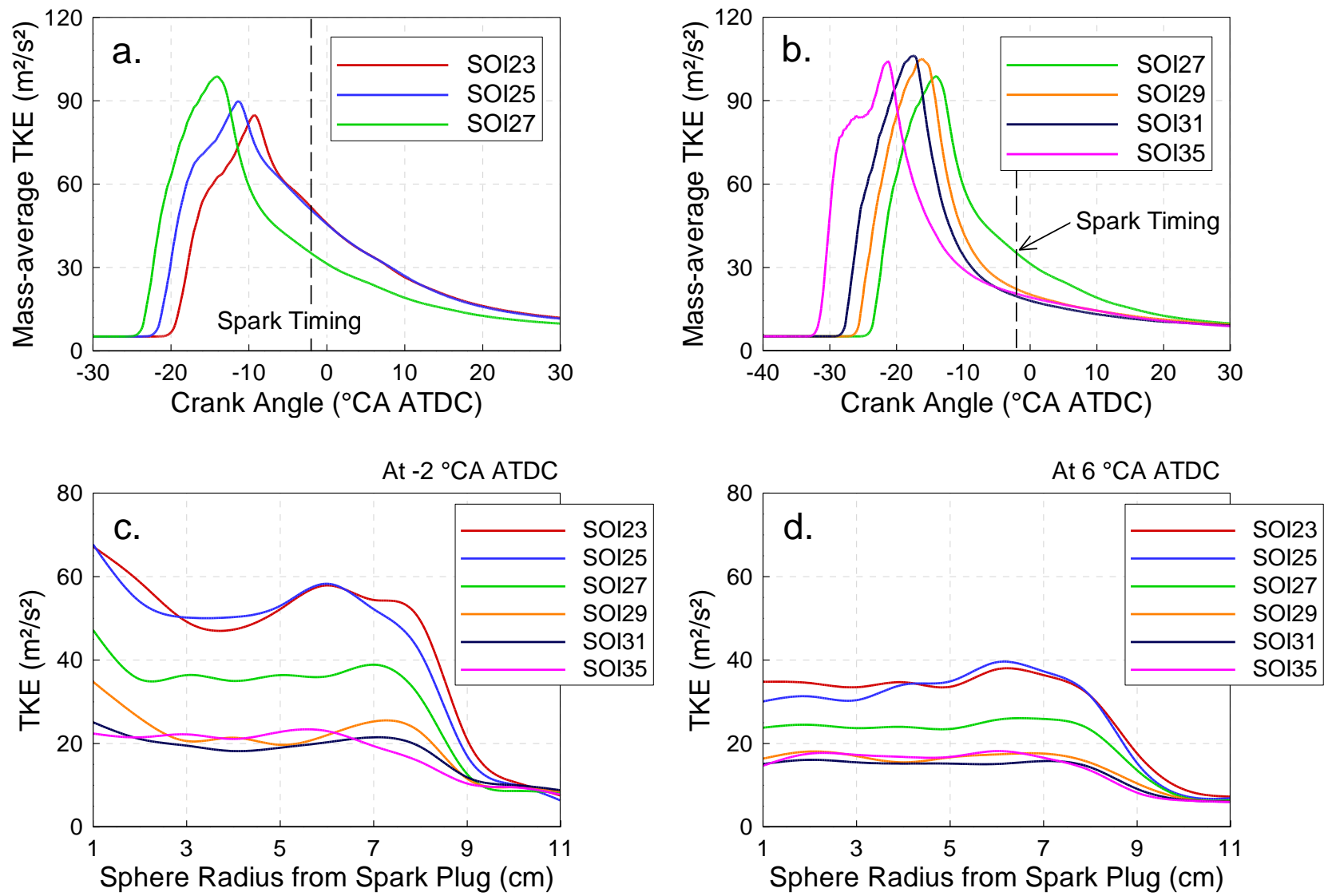

Fig. 6 Evolutions of TKE versus crank angle and distributions of TKE around the spark plug for different SOIs: (a, b) Mass averaged TKE over the entire cylinder; (c, d) Mass averaged TKE at different distances to the spark plug at two moments, one at ST (c), and one at $6{ }^{\circ} \mathrm{CAATDC}(\mathrm{d})$

The effects of SOI on flame propagation can be primarily ascribed to two aspects, i.e., the in-cylinder turbulence and fuel/air mixing, which are respectively represented by the turbulent kinetic energies (TKE) and the distribution 
of equivalence ratio $(\varnothing)$. The definition of $\varnothing$ is:

$$
\varnothing=\frac{2 \times \sum C+0.5 \times \sum H}{\sum O}
$$

where $\sum C$ denotes the total number of carbon atoms, $\sum H$ presents the total number of hydrogen atoms, and $\sum O$ is the total number of oxygen atoms.

The different combustion processes with various SOIs can be revealed by comparing their TKEs and $\emptyset$ distributions. It is expected that higher TKE results in a faster flame propagation speed through flame area enhancement [30]. Thus, the TKE is first compared among different SOIs in Fig. 6. When SOI is at -23 and $-25^{\circ} \mathrm{CA}$ ATDC, their averaged TKEs (Fig. 6a) after ST and the in-cylinder TKE distributions at ST (Fig. 6c) and $6{ }^{\circ} \mathrm{CAATDC}$ (Fig. 6d) are almost the same. When SOI is advanced before $-25^{\circ} \mathrm{CA}$ ATDC, the TKE gradually decreases until SOI at $-29^{\circ} \mathrm{CA}$ ATDC, as seen in Figs. 6a, 6c, and 6d. Once the SOI is further advanced before $-29{ }^{\circ} \mathrm{CA}$ ATDC, the averaged TKE and TKE distributions hardly changes for various SOIs, which indicates that the in-cylinder turbulence becomes insensitive to the change of SOI. Therefore, the effect of SOI on combustion behavior is mainly through its impact on the fuel/air mixing in the early SOI cases (earlier than $-29^{\circ} \mathrm{CA}$ ATDC), whereas in the later SOI cases, it affects the combustion process through both fuel/air mixing and flame/turbulence interaction (e.g. flame front is wrinkled by turbulence).

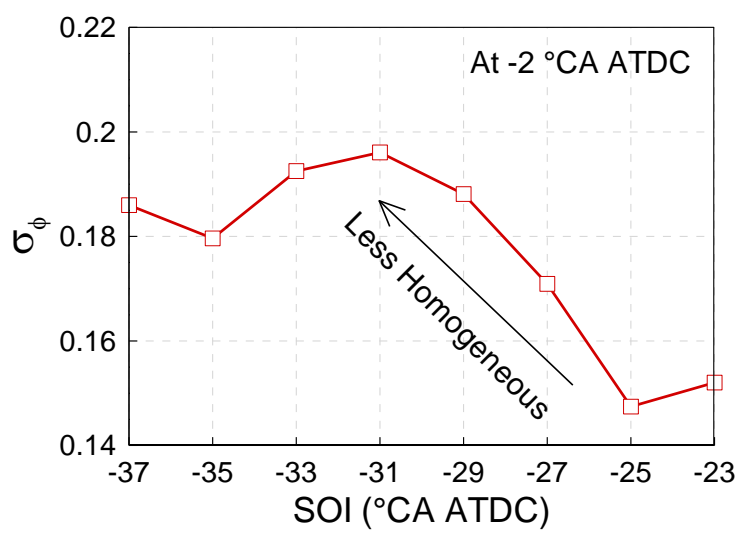

Fig. 7 Standard deviation of in-cylinder equivalence ratio $\left(\sigma_{\varnothing}\right)$ at ST for different SOIs

The effect of SOI on fuel/air stratification is quantified by the standard deviation of equivalence ratio $\left(\sigma_{\emptyset}\right)$, as shown in Fig. 7. It is acknowledged that the fuel distribution in the cylinder is usually more homogeneous with earlier SOI due to the longer mixing time. However, the $\sigma_{\emptyset}$ is lower when SOI is retarded from $-31{ }^{\circ} \mathrm{CA}$ ATDC, as shown in Fig. 7. It indicates that the fuel distribution in the cylinder is more homogeneous with more retarded SOI within the SOI range studied. Meanwhile, there is a non-monotonic variation of $\sigma_{\emptyset}$ for the SOI from -33 to $-37^{\circ} \mathrm{CA}$ ATDC. The fuel/air mixing behavior is closely related to the spray/bowl interaction, which will be explored in detail below.

Three representative cases with different SOIs are chosen for the analysis, and their evolutions of in-cylinder equivalence ratio are shown in Fig. 8. When SOI is at $-25^{\circ} \mathrm{CA}$ ATDC (Case A), the spray is targeted to the piston lip, and the spray flow is divided into two streams after impinging on the piston surface, as seen in Fig. 8a. The two split 
sprays gradually evolve into two backflow streams with the piston movement, which subsequently enhances fuel spreading and fuel-air mixing. Thus, for SOI at $-25{ }^{\circ} \mathrm{CA}$ ATDC, the fuel distribution in the bowl is relatively homogeneous before ST, as seen in Fig. 8 a. When SOI is retarded from -25 to $-23{ }^{\circ} \mathrm{CAATDC}$, the spray target moves downwards, and the fuel is still injected into the bowl region, resulting in a similar equivalence ratio distribution, i.e., a comparable $\sigma_{\emptyset}$. The similar fuel distribution (i.e., equivalence ratio) and TKE at ST are responsible for the similar pressure curves of SOI at -23 and $-25^{\circ} \mathrm{CA}$ ATDC.

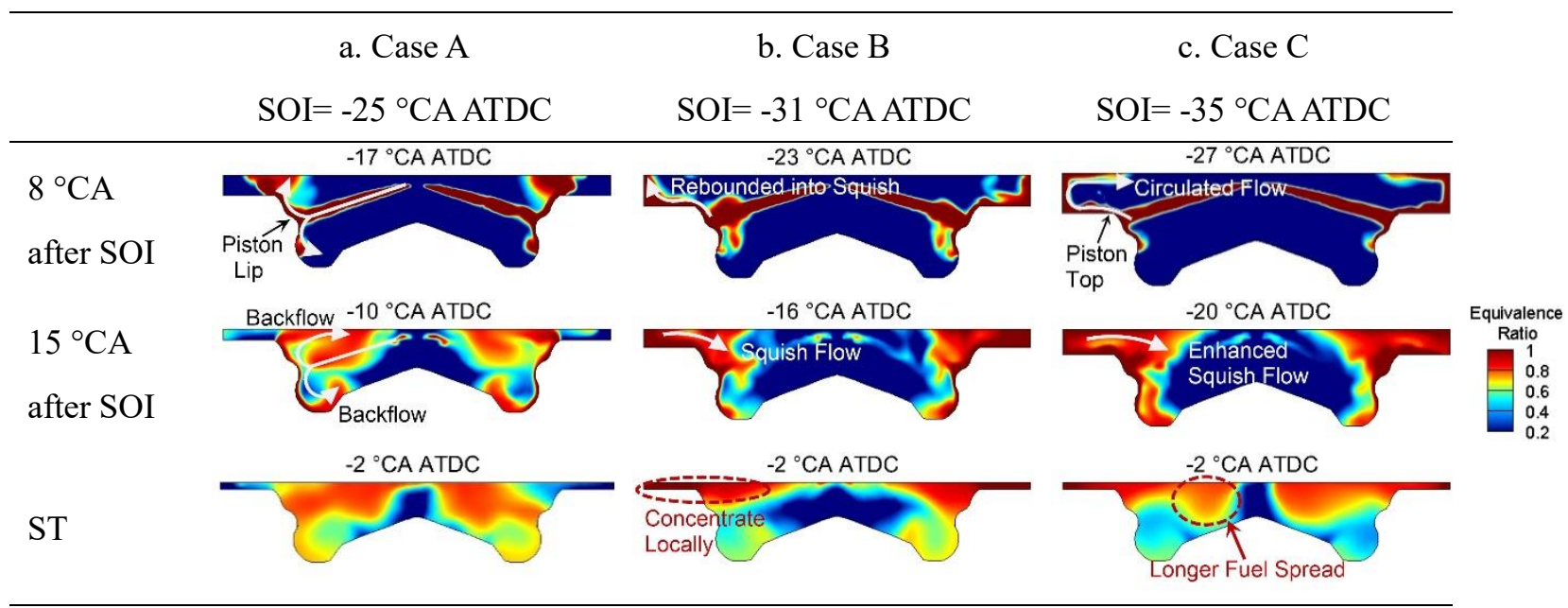

Fig. 8 Distributions of in-cylinder equivalence ratio under different SOIs in the vertical plane of Slice 1 (cf. Fig. 2b)

When SOI is advanced to $-31^{\circ} \mathrm{CA}$ ATDC (Case B), the spray target moves upwards, and most fuel is rebounded into the squish region after colliding with the piston lip, as shown in Fig. 8b. Although some fuel escapes out of squish under the squish flow during compression stroke, most of the fuel is still retained in the local region near the cylinder head at ST. When SOI is advanced to $-35^{\circ} \mathrm{CA}$ ATDC (Case C), the spray target further moves up towards the piston top. Most of the fuel is directly pushed into the squish region without collision with the piston lip. The injected fuel with high momentum produces a strong circulating flow in the squish region, as seen in Fig. 8c. The circulating flow can eventually enhance the strength of squish flow, resulting in more fuel being transported farther towards the cylinder axis. Thus, when SOI is advanced from -31 towards $-35^{\circ} \mathrm{CAATDC}$, the fuel distribution is more homogeneous. From the above discussion, the spray-guided system is acting in a similar way to a wall-guided system in the present engine configuration.

According to above discussion, the variation of spray target under different SOIs shows the dominant effect on fuel distribution and combustion process. Besides changing the SOI, adjusting the spray-included angle is an alternative approach to effectively control the spray target. To investigate this, numerical simulations were carried out over a range of spray-included angle for the case with SOI at $-35^{\circ} \mathrm{CA}$ ATDC (Case C). As seen in Fig. 9a, when SOI is fixed at $-35{ }^{\circ} \mathrm{CA}$ ATDC, although changing the spray half-included angle largely affects the peak TKE, the averaged TKEs at ST under various spray half-included angles are rather similar. Meanwhile, the TKEs at ST of all the cases with SOI at $-35{ }^{\circ} \mathrm{CA}$ ATDC cases are lower than that of the case with SOI at $-25^{\circ} \mathrm{CA}$ ATDC regardless of 
the spray half-included angle. It implies that the averaged TKE at ST is more sensitive to the interval between SOI and ST rather than the spray target.


Fig. 9 Comparison of averaged TKE and in-cylinder pressure for different SOI and spray half-included angles

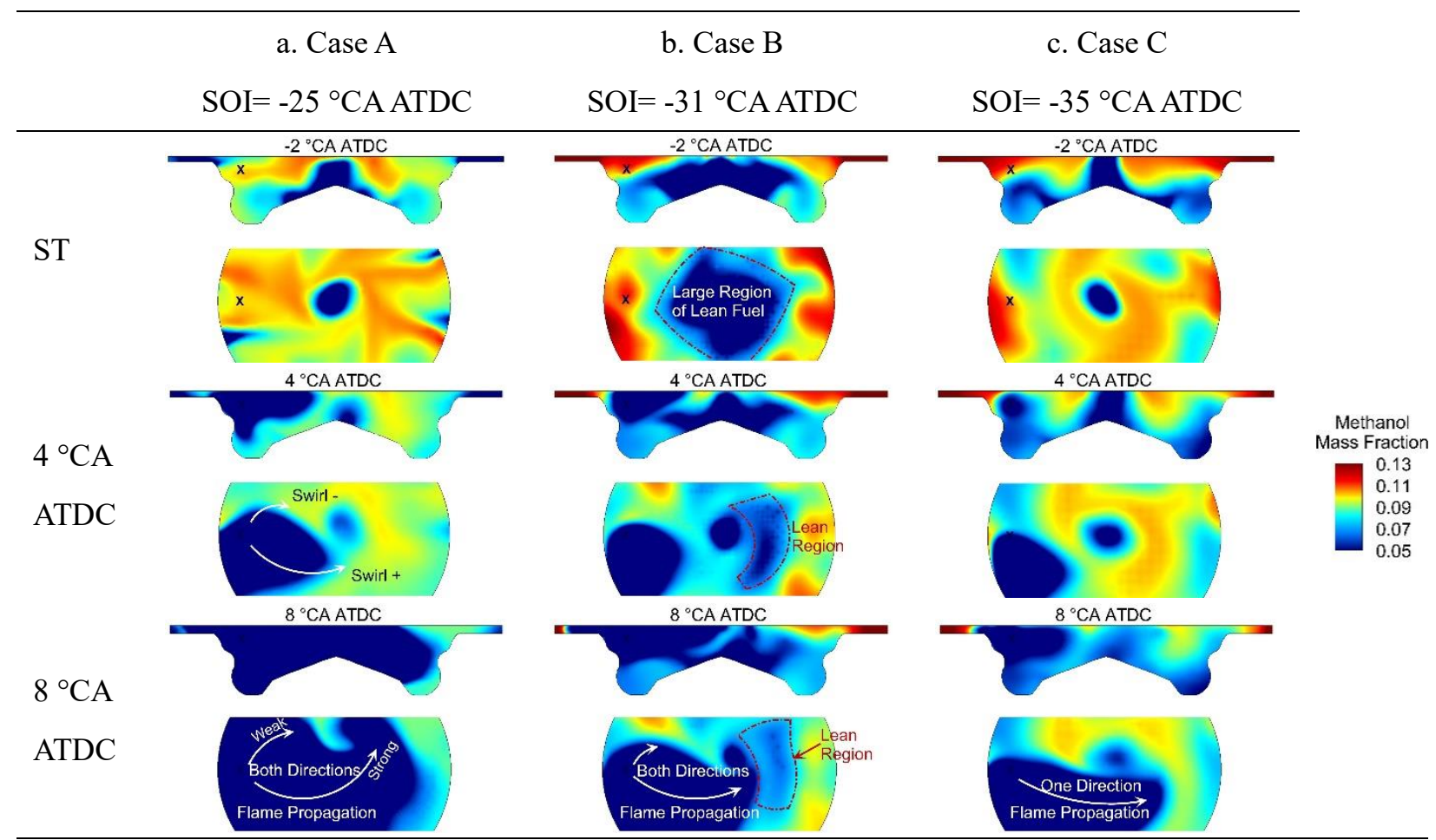

Fig. 10 Evolutions of in-cylinder methanol mass fraction under different SOIs in both vertical and horizontal planes of Slices 2 and 3 (the location of spark plug is denoted by "X")

When the spray-included angle is reduced, the spray target will move downwards just as retarding SOI. Thus, the variations of spray target with retarded SOI can be reproduced by reducing the spray half-included angle. As shown in Fig. 9 b, for the SOI at $-35^{\circ} \mathrm{CA}$ ATDC, when the spray half-included angle is reduced from $74^{\circ}$ to $65^{\circ}$, the peak pressure decreases in a similar way as retarding SOI to $-31{ }^{\circ} \mathrm{CA}$ ATDC. When the spray half-included angle is further decreased to $50^{\circ}$, the peak pressure increases substantially with the similar pressure trace as retarding SOI to 
$-25^{\circ} \mathrm{CAATDC}$. The same variation of the in-cylinder pressure curves obtained by reducing spray half-included angle and retarding SOI demonstrates the fact that, for the SOI range in this study, the effects of varying SOI on combustion process are more attributed to the variation of spray target (i.e., in-cylinder fuel distribution) rather than the change of in-cylinder turbulence.

Due to the significant effect of in-cylinder fuel distribution, the methanol mass fraction in the cylinder is used to represent the fuel/air mixing at ST and the flame propagation process after ignition. The in-cylinder distributions of methanol mass fraction in both vertical and horizontal planes (Slices 2 and 3, see in Fig. 2) are shown in Fig. 10. The flame propagation direction is closely associated with the in-cylinder swirl flow [31], and the initial swirl flow direction is named Swirl +, and the opposite swirl direction is named Swirl -, as shown in Fig. 10a. From the development of fuel consumption (the blue color region) in Fig. 10, it is found that the flame propagation process is quite different in Cases A, B, and C with different SOIs. The flames in Cases A and B propagate along both Swirl + and - directions, while only Swirl + direction of flame propagation is observed in Case C.

Under the high injection pressure, spray impingement is inevitable, as already illustrated in Fig. 8. After the high-momentum spray hits the chamber surface, it will be split into two separated flow streams with opposite directions in the horizontal plane as seen in Fig. 11. Due to the spray/bowl interaction, the initial in-cylinder swirl (anticlockwise direction from top view) is enhanced by the generated Swirl +, and Swirl - is created at the same time. The level of in-cylinder Swirl + is much larger than Swirl - due to the existence of initial in-cylinder swirl. After the end of injection, the swirl induced by spray (Swirl + and -) decays gradually. For the cases with earlier SOI, longer time is left for swirl dissipation. Thus, for the SOI case of $-35^{\circ} \mathrm{CA}$ ATDC, the generated Swirl - is totally offset at ST, and only one-way flame propagation along Swirl + is observed, which is different from the two-direction flame propagation in Cases A and B with retarded SOI.

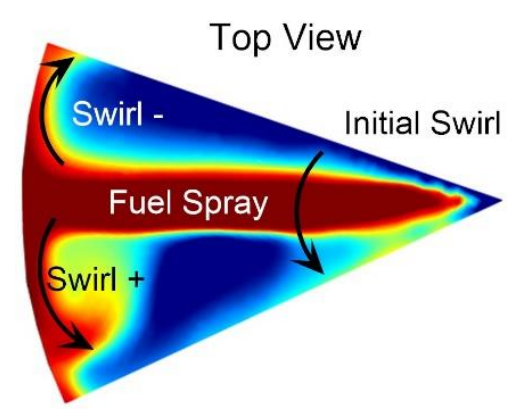

Fig. 11 In-cylinder swirl flow induced by spray in Slice 3 (Slice 3 can be seen in Fig. 2)

Besides the flame propagation directions are different under different SOIs, their flame propagation speeds are also different. According to the previous studies, under fuel-lean conditions, higher equivalence ratio leads to the faster flame propagation speed $[18,32]$. When SOI is at $-25^{\circ} \mathrm{CA}$ ATDC, the fuel mass fraction around the chamber center at ST is high as seen in Fig. 10, meanwhile the TKE is also the highest in this case, cf. Fig. 6, which gives rise to the highest turbulent burning velocity and the highest peak pressure. When SOI is advanced to $-31{ }^{\circ} \mathrm{CA}$ ATDC, a 
large region with low fuel concentration is formed in the cylinder center at the time of ST due to the spray-wall interaction, cf. the blue region in Fig. 10b. When the flame propagates across the cylinder center under the effect of in-cylinder swirl (at $8{ }^{\circ} \mathrm{CAATDC}$ ), the ultra-lean fuel region still exists in front of the flame for SOI at $-31{ }^{\circ} \mathrm{CA}$ ATDC, as seen in Fig. 10b. The low fuel concentration slows down the combustion rate, resulting in a slower pressure rise. As a result, the peak pressure of SOI at $-31{ }^{\circ} \mathrm{CA}$ ATDC is extremely low. When SOI is advanced to $-35{ }^{\circ} \mathrm{CA}$ ATDC, the fuel in the center becomes richer due to the enhanced squish flow and long mixing time as aforementioned. Thus, the flame propagation is faster than that of SOI at $-31^{\circ} \mathrm{CAATDC}$, as shown in Fig. 5 .

From above discussion, it can be concluded that the flame propagation direction is closely associated with the in-cylinder swirl, and the flame propagation speed is related to the magnitudes of turbulence and equivalence ratio. Under the medium load and speed, spray/bowl interaction has a very significant role in DISI engines, since it dictates not only the flame propagation speed by affecting in-cylinder fuel distribution and turbulence, but also the flame propagation direction by interfering the in-cylinder swirl flow.

\subsubsection{Effect of injection pressure}

In this section, two injection pressures are chosen for comparison under three different SOI conditions. As seen in Fig. 12, with the injection pressure of 1000 bar, the peak pressure decreases monotonically with advanced SOI, which is different from the complex non-monotonic variation of peak pressure at the injection pressure of $2000 \mathrm{bar}$. For the conventional DISI engines with early SOI, when injection pressure is decreased, the spray momentum is usually reduced and the spray breakup is weakened, resulting in a lower in-cylinder turbulence and slower fuel/air mixing. Accordingly, the HRR becomes slower and the in-cylinder peak pressure decreases [17]. However, this conclusion may not always be true when the spray/wall interaction is significant, such as the DISI cases with late SOI shown in Fig. 12.
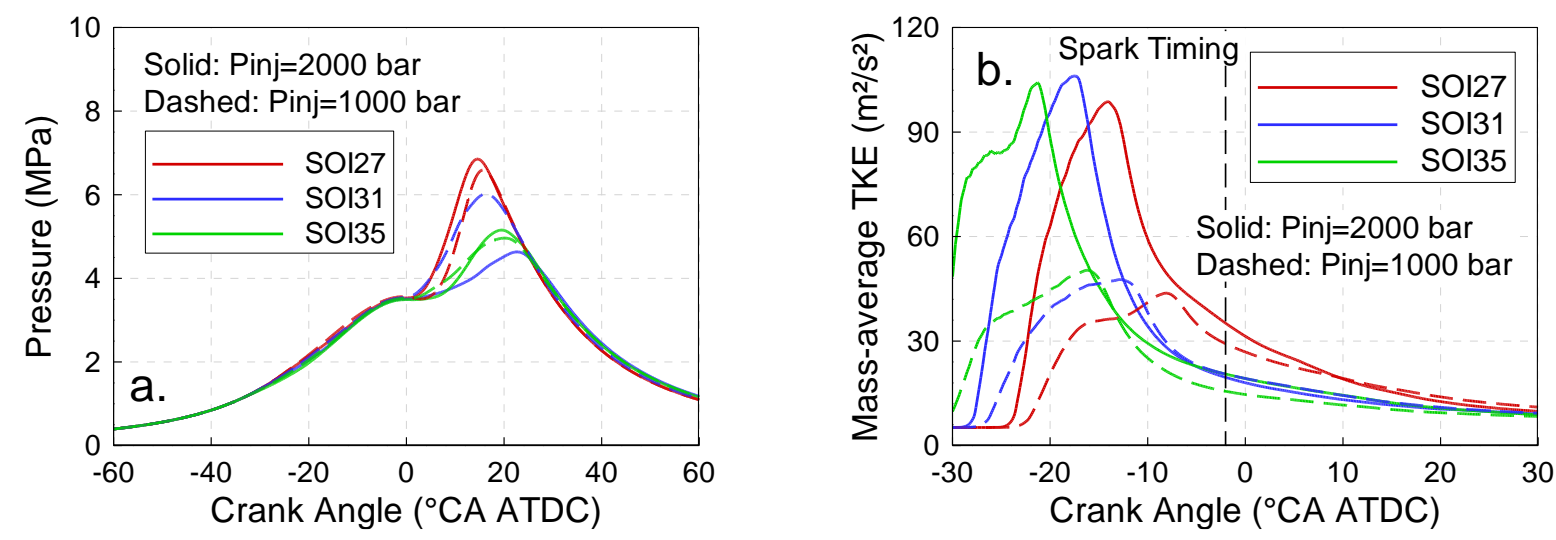

Fig. 12 Comparison of in-cylinder pressure and averaged TKE at different SOIs and injection pressures

Similar to the previous section, the mass-averaged TKE is firstly compared among the different cases to demonstrate the effect of injection pressure. Under the lower injection pressure, the monotonic decrease of TKE at 
ST with the advanced SOI is observed, which leads to a lower turbulent burning velocity and thereby lower incylinder pressure. For a given SOI, although the difference of peak TKE is obvious under various injection pressures, their TKEs at ST are much closer. Thus, the effect of injection pressures on combustion through its impact on TKE is less significant. In order to characterize the fuel distribution in the cylinder, the mass-averaged equivalence ratios along the piston bore radius under different SOIs and injection pressures are shown in Fig. 13. The radius of $0 \mathrm{~m}$ is the cylinder axis, and the radius of $0.065 \mathrm{~m}$ is the cylinder liner. For the SOI at $-27{ }^{\circ} \mathrm{CA}$ ATDC, all the injected fuel (from SOI to the end of injection) is targeted to the piston bowl regardless of injection pressure, so the fuel distributions are hardly affected by the injection pressure, as seen in Fig. 13a. Thus, for SOI at $-27{ }^{\circ} \mathrm{CA}$ ATDC, the slight lower in-cylinder peak pressure with reduced injection pressure is ascribed to the lower TKE.

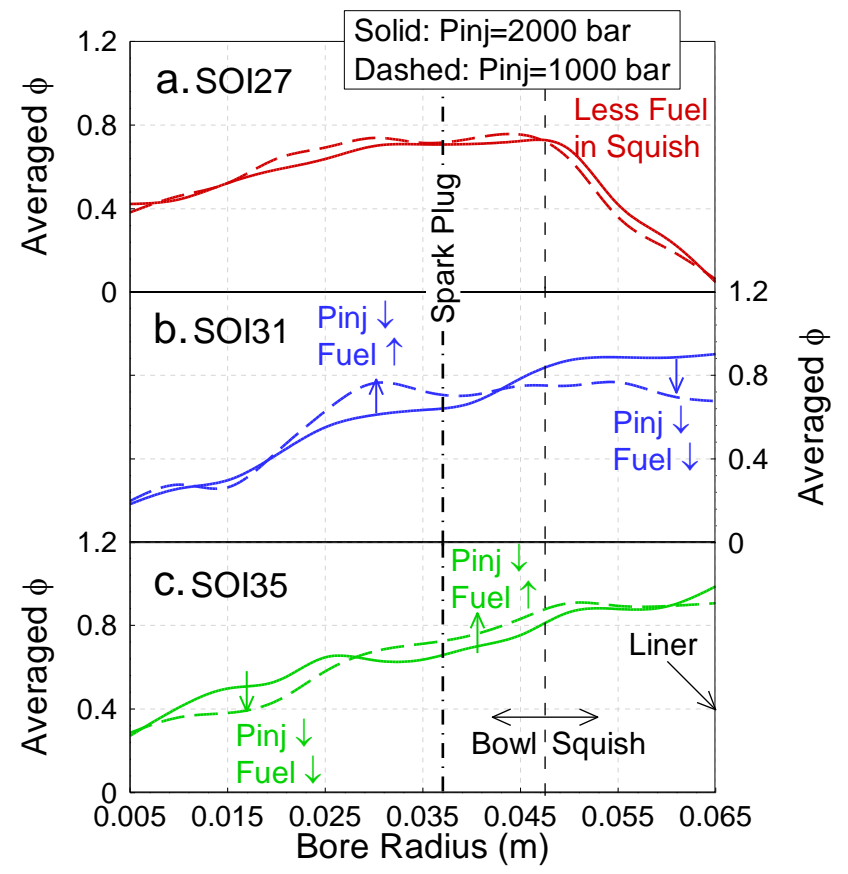

Fig. 13 Comparison of mass-averaged equivalence ratio along radius at ST among different SOIs and injection pressures $\left(P_{i n j}\right.$ denotes the injection pressure)

When SOI is at $-31{ }^{\circ} \mathrm{CA}$ ATDC, the injected fuel is rebounded into the squish region after colliding against the piston lip. When the injection pressure is reduced, the momentum of fuel spray decreases accordingly; thus, less fuel is delivered to the squish region after the spray/bowl collision, and more fuel is retained within the piston bowl. Meanwhile, due to the longer injection duration with the lower injection pressure, more fuel is injected at a later crank angle (closer to TDC), whose spray target is moved from the piston lip to the piston bowl as the piston moves towards TDC. As a result, larger fuel quantity enters into the piston bowl. For SOI at $-31^{\circ} \mathrm{CA}$ ATDC, the richer fuel (higher $\varnothing$ in Fig. 13b) near the spark plug under the lower injection pressure leads to the faster flame propagation, as seen in Fig. 12a.

For SOI at $-35{ }^{\circ} \mathrm{CA}$ ATDC, the spray directly targets to the squish, reducing the injection pressure will weaken the circulating flow and the squish flow. Thus, the fuel being squeezed out of squish penetrates a shorter distance, 
and more fuel concentrates around the spark plug. As seen in Fig. 13c, when the injection pressure of the SOI case at $-35^{\circ} \mathrm{CA}$ ATDC is reduced to $1000 \mathrm{bar}$, the equivalence ratio around spark plug is higher (i.e., more fuel) and the fuel concentration near the cylinder axis becomes lower. As a result, when the injection pressure of the SOI case at $35^{\circ} \mathrm{CA}$ ATDC is reduced, the initial pressure rise rate is faster, then the subsequent slope of pressure curve becomes lower, as seen in Fig. 12a.

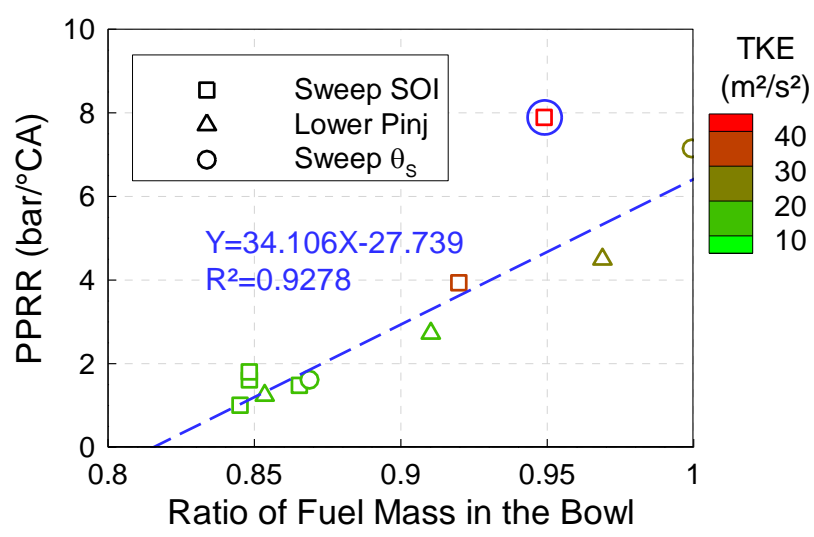

Fig. 14 Correlation between the ratio of the fuel mass in piston bowl to the total injected fuel mass at ST and PPRR for different cases

From above discussion, it appears that the more fuel in the bowl region (cf. Fig. 2), the faster flame propagation speed. Of all the cases considered above, the ratios of the fuel mass in the piston bowl at ST to the total injected fuel mass and PPRRs are plotted in Fig. 14 to demonstrate this correlation. In Fig. 14, the chosen cases contain the group of sweeping SOI (square symbols) from Fig. 5, the group of sweeping spray half-included angle (circle symbols) from Fig. 9, and the group of sweeping SOI with a lower injection pressure (triangle symbols) from Fig. 12. The color of these symbols represents the in-cylinder averaged TKE at ST. The case with excessively high TKE (i.e., the circled case in Fig. 14) is excluded to isolate the effect of in-bowl fuel mass on PPRR. A proportional correlation between the ratio of the fuel mass in the piston bowl (with respect to the total injected fuel mass) and PPRR can be clearly observed from Fig. 14.

Considering the effect of in-bowl fuel mass on the combustion intensity, when a methanol DISI engine is operated at low loads, it is suggested that the retarded SOI, reduced spray-included angle, and lower injection pressure should be adopted to enrich the fuel concentration in the piston bowl to achieve a stable combustion and satisfactory engine performance. Conversely, at high loads, the spray target should be moved upwards from the piston lip to the squish region to reduce the fuel mass in the piston bowl and the fuel distribution in the cylinder should be more homogeneous by advancing SOI, expanding spray-included angle, and increasing injection pressure. At the full load, the DISI engine should be operating in the premixed flame combustion mode like PFI engine, as revealed by Alkidas et al. [33]. 


\subsection{Effect of spark timing}

The ignition of fuel/air mixture in DISI engines is directly controlled by the ST, so the effects of ST on engine performance are investigated in this section. ITE, PPRR, and $\mathrm{NO}_{\mathrm{x}}$ emissions are compared among the cases with different STs in Fig. 15. Moreover, the combustion durations of these different cases are shown in Fig. 16. When ST is advanced, the combustion duration becomes shorter, especially for the cases with earlier SOI. Accordingly, the benefit of advancing ST in ITE is more obvious with the earlier SOI, as seen in Fig. 15a. However, when SOI is retarded while keeping the ST constant, the ITE decreases along with the shorter combustion duration. In order to explain the variation of ITE, the energy distributions of SOI at -25 and $-35{ }^{\circ} \mathrm{CA}$ ATDC with different STs are compared in Fig. 17. It is noting that the combustion efficiencies of all the cases in Fig. 17 are above 99\%, so they can be regarded as complete combustion.

As seen in Fig. 17, when the ST is advanced, the combustion temperature becomes higher, so the heat transfer loss increases accordingly. Meanwhile, the exhaust loss decreases gradually due to the advanced ignition timing and shorter combustion duration (higher turbulent burning velocity) [34]. As seen in Fig. 17a, when SOI is within -29$-37^{\circ} \mathrm{CA}$ ATDC, the reduction of exhaust loss outweighs the increase of heat transfer loss with the earlier ST, so the ITE finally increases. On the contrary, when SOI is during $-25--29^{\circ} \mathrm{CA}$ ATDC, the increase of heat transfer loss is more significant, resulting in the reduction of ITE.

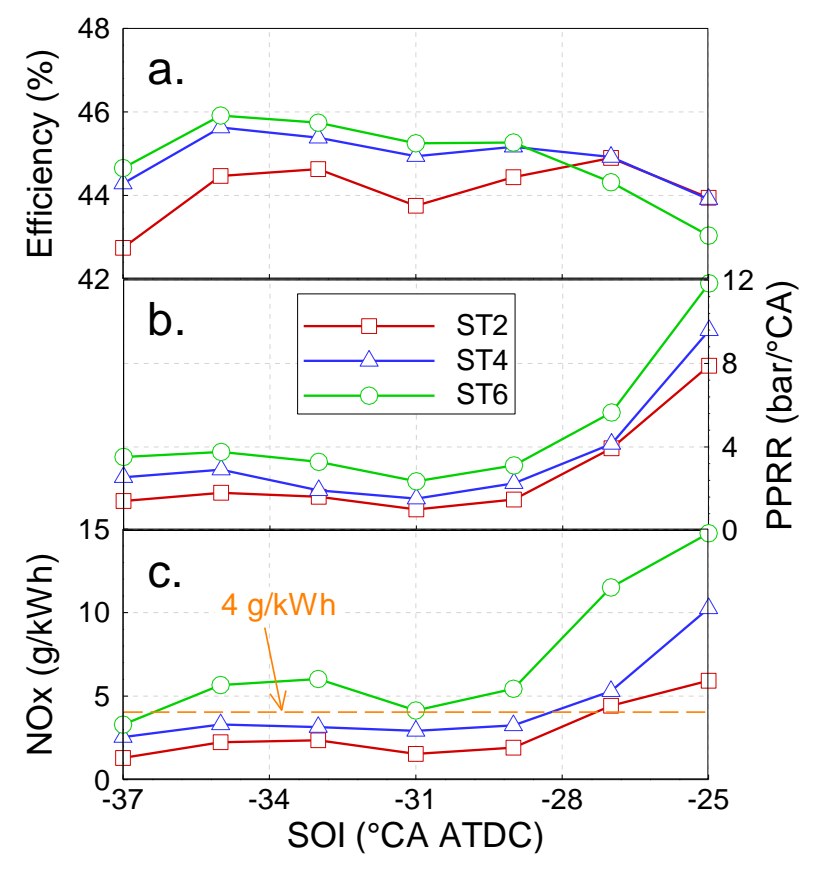

Fig. 15 Variations of ITE, PPRR, and $\mathrm{NO}_{\mathrm{x}}$ versus SOI under different STs (ST2, ST4 and ST6 denote respectively the spark timing at $-2,-4$ and $-6{ }^{\circ} \mathrm{CA}$ ATDC)

At a fixed ST of -4 or $-6{ }^{\circ} \mathrm{CA}$ ATDC, when SOI is advanced from -25 to $-35{ }^{\circ} \mathrm{CA}$ ATDC, the increased ITE is attributed to the more dominant reduction of heat transfer loss. Thus, the reduction of heat transfer loss is significant to improve ITE, which can be achieved by optimizing the piston geometry to reduce the surface-to-volume ratio. 
Whereas, when the heat transfer loss is reduced, most of the saved energy is preserved in the exhaust gases rather than converted into the output work, resulting in the larger exhaust loss, as seen in Fig. 17. Although increasing the specific heat ratio can increase the work extraction from the exhaust gases to some extent [35], exhaust energy recovery is more important for the further improvement of ITE [36].

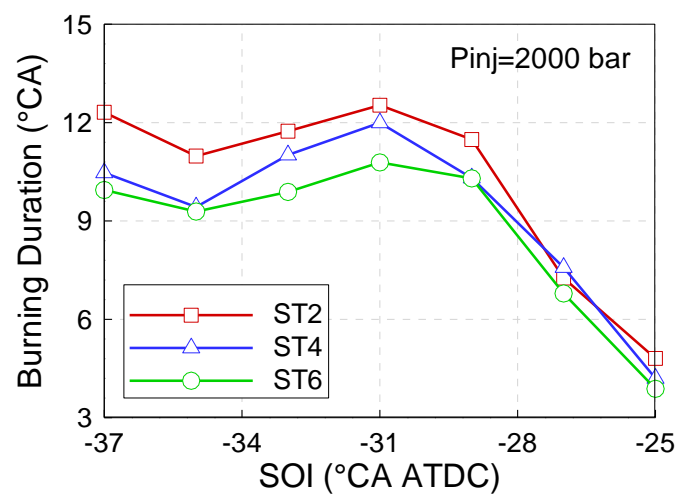

Fig. 16 Variation of combustion duration under different SOIs and STs
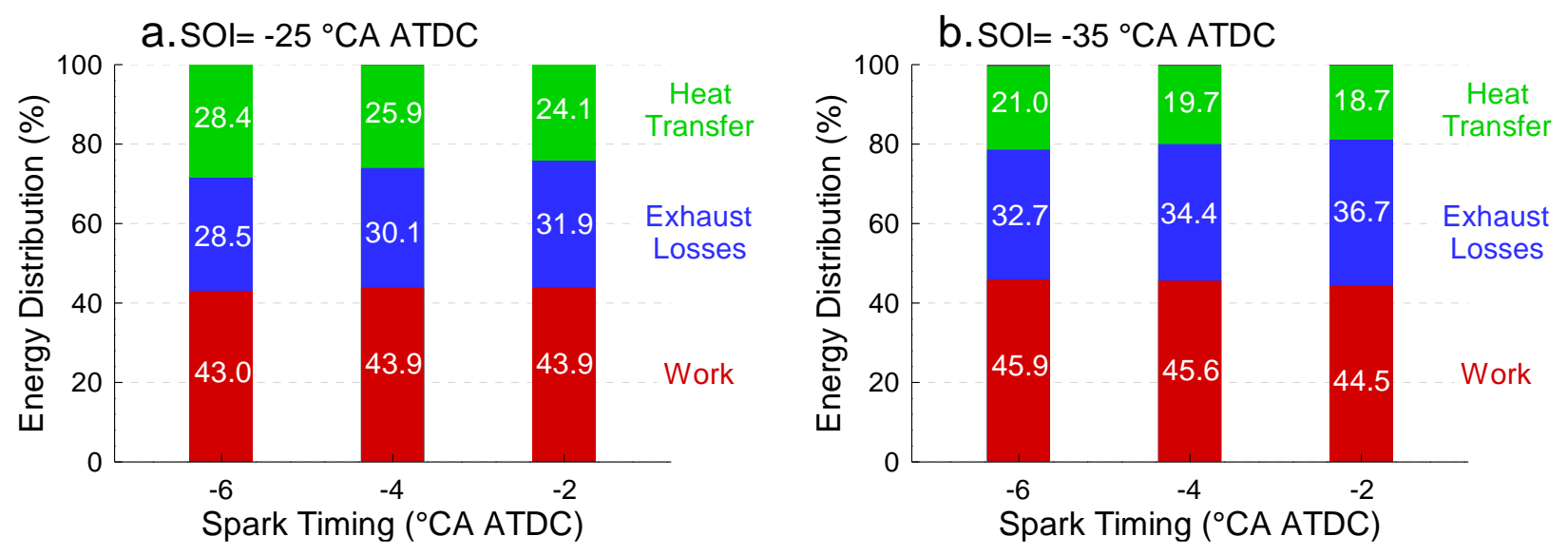

Fig. 17 Energy distribution at different SOIs and STs

The $\mathrm{NO}_{\mathrm{x}}$ emissions in all cases are excessively high due to the high combustion temperature, so EGR and/or after-treatment systems should be introduced. When only the after-treatment systems are applied to the current cases, and the conversion efficiency of $\mathrm{NO}_{\mathrm{x}}$ emissions in the after-treatment system is assumed to be $90 \%$ [37]. In order to meet the Euro 6 emission regulation [38], $4 \mathrm{~g} / \mathrm{kWh}$ of $\mathrm{NO}_{\mathrm{x}}$ before after-treatment would be the maximum tolerant value based on our assumption. As seen in Fig. 15, most cases with ST at -2 and $-4{ }^{\circ} \mathrm{CA}$ ATDC satisfy the $\mathrm{NO}_{\mathrm{x}}$ limit except for the cases with late SOI. Once the ST is further advanced to $-6{ }^{\circ} \mathrm{CA}$ ATDC, all the cases produce unacceptably high $\mathrm{NO}_{\mathrm{x}}$ emissions.

Overall, the variations of ITE, PPRR, and $\mathrm{NO}_{\mathrm{x}}$ with respect to the variation of SOI are similar under different STs, as shown in Fig. 15, and an advanced SOI is more favorable to engine performance. The PPRR and $\mathrm{NO}_{\mathrm{x}}$ are higher at the earlier ST due to the higher combustion temperature and faster flame propagation. Overall, when ST is advanced from -2 to $-4{ }^{\circ} \mathrm{CAATDC}$, the fuel efficiency will increase with a slight penalty on PPRR and $\mathrm{NO}_{\mathrm{x}}$ emissions. 
However, when ST is further advanced to $-6{ }^{\circ} \mathrm{CA}$ ATDC, the $\mathrm{NO}_{\mathrm{x}}$ emissions exceed the acceptable limit as aforementioned. Thus, under the medium load and speed, the optimal operating point is the ST at $-4{ }^{\circ} \mathrm{CA}$ ATDC and an advanced SOI at $-35{ }^{\circ} \mathrm{CA}$ ATDC. The results reveal the significance of simultaneously optimizing both fuel injection and spark ignition to improve engine performance $[39,40]$.

\section{Conclusions}

The combustion characteristics of a highly stratified methanol DISI engine with a high compression ratio is investigated in this study. The effects of SOI, spray half-included angle, injection pressure, and ST on fuel distribution, flame propagation, fuel efficiency, and $\mathrm{NO}_{\mathrm{x}}$ emissions are evaluated in detail, and the strategies to achieve the satisfactory engine performance under different operating conditions are proposed. The conclusions are drawn as follows:

1. The combustion process of methanol DISI engine is highly sensitive to the variation of SOI, which is closely associated with the in-cylinder turbulence and fuel distribution. When SOI is later than $-29{ }^{\circ} \mathrm{CA}$ ATDC, the effect of SOI on combustion process is through its impacts on both in-cylinder turbulence and fuel distribution. When SOI is advanced before $-29^{\circ} \mathrm{CAATDC}$, the effect of SOI on the flame propagation is mainly through its impact on fuel distribution.

2. Spray/bowl interaction plays a significant role in DISI engines, since it not only dominates the flame propagation speed by affecting in-cylinder fuel distribution and turbulence intensity, but also it determines the flame propagation direction by interfering in-cylinder swirl flow. The effects of SOI on combustion process are more dependent on its impact on the in-cylinder fuel distribution which is affected by the spray target. Thus, retarding SOI shows similar combustion process as reducing spray half-included angle.

3. The TKE at ST is similar under different injection pressures, so the in-cylinder fuel distribution is the dominant factor on combustion process. When the spray is targeted inside the bowl with retarded SOI, reducing injection pressure cannot affect the fuel distribution obviously. When the spray target is moved towards the squish with advanced SOI, reducing injection pressure could increase the combustion temperature to some extent, resulting in a higher PPRR and $\mathrm{NO}_{x}$.

4. The flame propagates from the spark plug towards the cylinder axis along the in-cylinder swirl direction, and larger fuel mass in the piston bowl causes a more intensive combustion process. Thus, the in-bowl fuel mass should be increased at low loads to achieve more stable combustion and satisfactory engine performance, which can be achieved by retarding SOI, reducing spray-included angle, and lowering injection pressure. Conversely, with the increase of operating load, the in-bowl fuel mass should be reduced accordingly by moving the spray target towards the squish.

5. Under the medium load and speed, ITE, PPRR, and $\mathrm{NO}_{\mathrm{x}}$ emissions are all improved with advanced SOI. This is because the reduced combustion temperature with advanced SOI leads to lower heat transfer loss and more moderate combustion rate. Meanwhile, advancing ST appropriately will improve fuel efficiency with a slight 
penalty on PPRR and $\mathrm{NO}_{\mathrm{x}}$. Therefore, simultaneous optimization of fuel injection and spark ignition is promising to further improve engine performance.

\section{Acknowledgments}

The work is financially supported in part by the King Abdullah University of Science and Technology (KAUST) Office of Sponsored Research (OSR) under Award No. OSR-2017-CPF-3319 and in part by the Swedish Energy Agency. The authors would like to thank Convergent Science for providing licenses for the CONVERGE software.

\section{Reference}

[1] Matsumoto A, Moore WR, Lai M, et al. Spray characterization of ethanol gasoline blends and comparison to a CFD model for a gasoline direct injector. SAE Int J Engine. 2010;3:402-25.

[2] Zhao F, Lai M, Harrington DL. Automotive spark-ignited direct-injection gasoline engines. Prog Energ Combust. 1999;25(5):437-562.

[3] Johansson A. Challenges and Advantages of Stratified Combustion in Gasoline Direct-Injected Engines: Chalmers University of Technology, 2017.

[4] Alkidas AC, El Tahry SH. Contributors to the fuel economy advantage of DISI engines over PFI engines. SAE Tech Paper 2003-01-3101; 2003.

[5] Awad OI, Mamat R, Ali OM, et al. Alcohol and ether as alternative fuels in spark ignition engine: A review. Renew Sust Energ Rev. 2017;82:2586-605.

[6] Zhao H. Advanced direct injection combustion engine technologies and development: gasoline and gas engines: Elsevier, 2009.

[7] Yao C, Pan W, Yao A. Methanol fumigation in compression-ignition engines: A critical review of recent academic and technological developments. Fuel. 2017;209:713-32.

[8] Li Y, Jia M, Chang Y, et al. Principle of determining the optimal operating parameters based on fuel properties and initial conditions for RCCI engines. Fuel. 2018;216:284-95.

[9] Verhelst S, Turner JW, Sileghem L, et al. Methanol as a fuel for internal combustion engines. Prog Energ Combust. 2019;70:43-88.

[10] Shamun S, Shen M, Johansson B, et al. Exhaust PM emissions analysis of alcohol fueled heavy-duty engine utilizing PPC. SAE Int J Engine. 2016;9:2142-52.

[11] Liu S, Clemente ERC, Hu T, et al. Study of spark ignition engine fueled with methanol/gasoline fuel blends. Appl Therm Eng. 2007;27:1904-10.

[12] Liu H, Wang Z, Long Y, et al. Dual-Fuel Spark Ignition (DFSI) combustion fuelled with different alcohols and gasoline for fuel efficiency. Fuel. 2015;157:255-60.

[13] Vancoillie J, Demuynck J, Sileghem L, et al. The potential of methanol as a fuel for flex-fuel and dedicated spark-ignition engines. Appl Energ. 2013;102:140-9. 
[14] Sileghem L, Ickes A, Wallner T, et al. Experimental investigation of a DISI production engine fuelled with methanol, ethanol, butanol and iso-stoichiometric alcohol blends. SAE Tech Paper 2015-01-0768; 2015.

[15] Björnestrand L. Efficiency and Emission Analysis of a Methanol Fuelled Direct Injection Spark Ignition Heavy Duty Engine: Lund University, 2017.

[16] Splitter DA. High efficiency RCCI combustion: The University of Wisconsin-Madison, 2012.

[17] Spicher U, Magar M, Hadler J. High pressure gasoline direct injection in spark ignition engines-efficiency optimization through detailed process analyses. SAE Int J Engine. 2016;9:2120-8.

[18] Drake MC, Fansler TD, Lippert AM. Stratified-charge combustion: modeling and imaging of a spray-guided direct-injection spark-ignition engine. P Combust Inst. 2005;30(2):2683-91.

[19] Richards K, Senecal P, Pomraning E. CONVERGE 2.4 Manual. Convergent Science, Inc, Madison, WI. 2018.

[20] Han Z, Reitz RD. Turbulence modeling of internal combustion engines using RNG $\kappa-\varepsilon$ models. Combust Sci Technol. 1995;106(4-6):267-95.

[21] Ricart LM, Reltz RD, Dec JE. Comparisons of diesel spray liquid penetration and vapor fuel distributions with in-cylinder optical measurements. J Eng Gas Turb Power. 2000;122(4):588-95.

[22] Schmidt DP, Rutland C. A new droplet collision algorithm. J Comput Phys. 2000;164(1):62-80.

[23] Amsden AA, O'rourke P, Butler T. KIVA-II: A computer program for chemically reactive flows with sprays. Los Alamos National Lab., NM (USA); 1989.

[24] O'Rourke PJ, Amsden A. A spray/wall interaction submodel for the KIVA-3 wall film model. SAE Technical Paper 2000-01-0271; 2000.

[25] Colin O, Truffin K. A spark ignition model for large eddy simulation based on an FSD transport equation (ISSIMLES). P Combust Inst. 2011;33(2):3097-104.

[26] Colin O, Benkenida A, Angelberger C. 3D modeling of mixing, ignition and combustion phenomena in highly stratified gasoline engines. Oil Gas Sci Technol. 2003;58(1):47-62.

[27] Heywood JB. Internal combustion engine fundamentals: McGraw-Hill Education, 1988.

[28] Shamun S, Haşimoğlu C, Murcak A, et al. Experimental investigation of methanol compression ignition in a high compression ratio HD engine using a Box-Behnken design. Fuel. 2017;209:624-33.

[29] Liu H, Wang Z, Long Y, et al. Methanol-gasoline Dual-fuel Spark Ignition (DFSI) combustion with dualinjection for engine particle number (PN) reduction and fuel economy improvement. Energy. 2015;89:1010-7.

[30] Kim T, Song J, Park S. Effects of turbulence enhancement on combustion process using a double injection strategy in direct-injection spark-ignition (DISI) gasoline engines. Int J Heat Fluid Flow. 2015;56:124-36.

[31] Zeng W, Sjöberg M, Reuss DL, et al. The role of spray-enhanced swirl flow for combustion stabilization in a stratified-charge DISI engine. Combust Flame. 2016;168:166-85.

[32] Huang Y, Hong G, Huang R. Effect of injection timing on mixture formation and combustion in an ethanol direct injection plus gasoline port injection (EDI+ GPI) engine. Energy. 2016;111:92-103.

[33] Alkidas AC. Combustion advancements in gasoline engines. Energ Convers Manage. 2007;48(11):2751-61. 
[34] Li Y, Jia M, Chang Y, et al. Thermodynamic energy and exergy analysis of three different engine combustion regimes. Appl Energ. 2016;180:849-58.

[35] Caton JA. Maximum efficiencies for internal combustion engines: Thermodynamic limitations. Int J Engine Res. 2017:1468087417737700.

[36] Song J, Gu C. Parametric analysis of a dual loop Organic Rankine Cycle (ORC) system for engine waste heat recovery. Energ Convers Manage. 2015;105:995-1005.

[37] Oh J, Lee K. Spray characteristics of a urea solution injector and optimal mixer location to improve droplet uniformity and NOx conversion efficiency for selective catalytic reduction. Fuel. 2014;119:90-7.

[38] Commission Regulation (EU) No 582/2011 (Euro VI) Off J Euro Union (May 25, 2011) No. 582/2011.

[39] Li J, Gong C, Su Y, et al. Effect of injection and ignition timings on performance and emissions from a sparkignition engine fueled with methanol. Fuel. 2010;89(12):3919-25.

[40] Gong C, Liu J, Peng L, et al. Numerical study of effect of injection and ignition timings on combustion and unregulated emissions of DISI methanol engine during cold start. Renew Energ. 2017;112:457-65. 